\title{
Endoscopic removal of cisternal neurocysticercal cysts
}

\author{
Technical note
}

\author{
Tooraj Gravori, M.D., Thomas Steineke, M.D., Ph.D., and Marvin Bergsneider, M.D. \\ Harbor-UCLA Medical Center and Division of Neurosurgery, University of California, Los Angeles, \\ California
}

\begin{abstract}
The authors report the use of neuroendoscopy for the treatment of cisternal neurocysticercosis. The utilization of the endoscope is meant to provide a safe and minimally invasive procedure for the removal of symptomatic cysts, minimizing morbidity and mortality relating to the natural history of the disease, as well as possibly avoiding a more extensive standard open craniotomy.

A retrospective review of three cases of cisternal cysticercosis was performed. The presenting signs and symptoms, neuroimaging findings, endoscopic treatment, and outcomes are presented. The technical aspect of the endoscopic resection is described, with visual support provided by intraoperative video. Cerebrospinal fluid shunt placement was avoided in one patient in whom complete resection of the cyst was required. In one patient there were extensive interhemispheric and premesencephalic cisternal cysts, some of which could not be removed because of their multiplicity and extensive adhesions. Despite the intraoperative rupture of cysts, there were no cases of arachnoiditis or ventriculitis postoperatively.

The minimally invasive endoscopic resection of cisternal cysticercosis is possible and effective in selected patients. Although the most appropriate treatment of cisternal cysticercosis remains a controversial issue, endoscopic resection should be considered as a primary treatment in symptomatic patients in cases that are amenable to endoscopic intervention.
\end{abstract}

\section{KEY WORDS • cysticercosis - subarachnoid space • neurocysticercosis • endoscopy • minimally invasive}

In endemic regions, $\mathrm{NCC}$ is a common parasitic disease that can manifest numerous clinical signs and symptoms. ${ }^{14,30,35}$ The most common presentation is seizure secondary to parenchymal cysts. ${ }^{22,27}$ Cisternal involvement is less common and is usually accompanied by parenchymal cysts and possibly intraventricular cysts. It is assumed that cisternal cysts came to reach this final anatomical location by passing through the ventricular system. Although cisternal cysts can be solitary, they much more commonly occur as a localized conglomeration of cysts or as a diffuse infestation of the subarachnoid spaces. ${ }^{30}$ Patients with cisternal NCC involvement usually present with hydrocephalus, ${ }^{19,35}$ either caused by the shear number of cysts occluding CSF movement or, more commonly, a chronic arachnoiditis associated with cyst degeneration. ${ }^{40}$ Rarely, the local mass resulting from a localized pocket of subarachnoid cysts can cause neurological symptoms due to compression of the brainstem, cranial nerves, or the ven-

Abbreviations used in this paper: $\mathrm{CSF}=$ cerebrospinal fluid; $\mathrm{CT}=$ computerized tomography; $\mathrm{MR}=$ magnetic resonance; $\mathrm{NCC}=$ neurocysticercosis; $\mathrm{VP}=$ ventriculoperitoneal . tricular pathways. ${ }^{10,30}$ Like the other forms of NCC, brain compression caused by the mass effect of the cysts can be aggravated by an inflammatory arachnoiditis. It is thought that the latter can lead to adjacent brain ischemic conditions caused by a microvasculitis. $1,3-7,10,11,13,17,18,20,21,23-25,28,35$ As with other focal entities, the neurological presentation will vary based on the cyst's neuroanatomical location. Cysts present in the basilar cisterns have been reported to cause hemifacial spasm, trigeminal neuralgia, and brainstem compression. $27,32,33,40$

The management of cisternal disease varies depending on clinical experience and institutional bias, because the literature provides only anecdotal reports. In most cases, either the extent of involvement or the advanced-stage disease precludes surgical intervention. Previously open surgical attempts to remove NCC cysts from the subarachnoid spaces were reported to be futile and often dangerous. ${ }^{37}$ Resection of cysts densely adherent to the brainstem or cranial nerves was not possible without causing significant neural damage. Overall, the morbidity rate associated with extraparenchymal cysticercosis is greater than that for parenchymal disease..$^{28,40}$ 
In this report, we describe the successful endoscopic management of three patients with cisternal (subarachnoid) NCC. Present in each case was a localized accumulation of cysts in a cisternal space adjacent to the ventricular system. The principal goal for the treatment was to remove safely the cisternal lesions, thereby reducing the morbidity associated with cystic mass effect, degeneration, inflammation, and expansion. A secondary goal was to reduce the need for procedures involving placement of a CSF shunt by decreasing the obstruction to CSF. This was achieved by combining cyst resection with direct treatment of the hydrocephalus - that is, a third ventriculostomy and/or septum pellucidotomy.

\section{CLINICAL MATERIAL AND METHODS}

\section{Presentation and Preoperative Management}

We reviewed the medical records of three cases in which patients with symptomatic cisternal cysticercosis underwent endoscopic surgery, performed by the senior author (M.B.) at Harbor-UCLA Medical Center between January 1997 and December 2001. The patients were adults who had emigrated from Mexico to the Los Angeles area. In general, all three patients presented with progressive symptoms relating to mass effect and hydrocephalus. Each patient underwent placement of a ventriculostomy drain on admission for the treatment of hydrocephalus, and intravenous dexamethasone and antiepileptic therapy was initiated preoperatively. None received any anthelmintic agents. A summary of clinical data, neuroimaging findings, surgical management, and outcome is provided in Table 1.

\section{General Endoscopic Technique and Findings}

In each case, the cisternal cysts were approached via a transventricular corridor (Figs. 1-3). In two cases (Cases 1 [Fig. 1] and 3 [Fig. 3], Table 1), cysts superior or anteri- or to the third ventricle were reached by perforating the overlying septum pellucidum (Videos 1 and 3). In the patient in Case 2 (Video 2), the quadrigeminal cistern was entered by opening the extended trigone ependyma. Once within the cistern, the NCC cysts were easily identified. Both flexible- and rigid-lens endoscopes were used. All cysts were ruptured in the process of resection. The cystic yellowish content and scolex were evacuated. The cyst wall was resected using a micrograsper that extended through the working port of the endoscope.

In two patients (Cases 1 and 2), multiple thin-walled, ballottable cysts were encountered. The cysts were torn when a transendoscopic instrument was used to grasp them. This allowed evacuation of the largest cysts and subtotal removal of a few of the smaller cysts that had been inaccessible. In Case 1, small cysts encountered behind (from the endoscopic perspective) the anterior cerebral vessels could not be completely removed. As with intraventricular cysts ${ }^{8,9}$ the lesions were removed by withdrawing the endoscope instead of attempting to pull the cyst through the small instrumentation channel of the endoscope.

In Case 3, the cyst within the velum interpositum (tela choroidea of the third ventricle) (Video 3) was approached using two frontal burr holes for a two-port technique. Unlike the other two cases, this cyst showed a thick ring enhancement on gadolinium-enhanced MR imaging. A rigid-lens $30^{\circ}$ angled endoscope was passed through one port and standard microsurgical instrumentation passed through a No. $14 \mathrm{~F}$ peel-away sheath via the other port. The cyst was quite thick walled, which allowed for grosstotal removal.

No surgery-related complications resulting from endoscopic resection occurred. In the event of minor bleeding, continuous irrigation was effective in achieving hemostasis within minutes. In two of three patients (Cases 1 and 3 ), VP shunts were inserted. In one patient, who was returned to the operating room after resolution of meningi-

TABLE 1

Summary of clinical, operative, and outcome data in three patients with NCC

\begin{tabular}{|c|c|c|c|c|c|c|}
\hline \multirow{2}{*}{$\begin{array}{l}\text { Case } \\
\text { No. }\end{array}$} & \multirow{2}{*}{$\begin{array}{l}\text { Age (yrs), } \\
\text { Sex }\end{array}$} & \multirow{2}{*}{$\begin{array}{c}\text { Key } \\
\text { Symptoms }\end{array}$} & \multicolumn{2}{|c|}{ Findings } & \multirow{2}{*}{$\begin{array}{c}\text { Operative } \\
\text { Management }\end{array}$} & \multirow[b]{2}{*}{ Outcome } \\
\hline & & & Clinical & Neuroimaging & & \\
\hline 1 & $41, \mathrm{M}$ & $\begin{array}{l}6 \text { mos of progressive } \\
\text { visual loss, headache, } \\
\text { vomiting, vertigo, \& } \\
\text { truncal ataxia }\end{array}$ & $\begin{array}{l}\text { It facial droop, } \\
\text { papilledema, \& } \\
\text { peripheral vision } \\
\text { loss }\end{array}$ & $\begin{array}{l}\text { MR w/ nonenhancing cysts in } \\
\text { interhemispheric fissure \& } \\
\text { lt perimesencephalic fissure; } \\
\text { compression of chiasm \& } \\
\text { 1t optic nerve }\end{array}$ & $\begin{array}{l}\text { endoscopic removal } \\
\text { of cysts w/in lamina } \\
\text { terminalis cistern via } \\
\text { rt frontal burr hole; } \\
\text { VP shunt was placed }\end{array}$ & $\begin{array}{l}\text { improved vision \& } \\
\text { facial weakness, } \\
\text { nausea \& ataxia at } \\
2 \text { wk-follow up }\end{array}$ \\
\hline 2 & $63, \mathrm{M}$ & $\begin{array}{l}6 \text { mos of dizziness \& } \\
\text { headache }\end{array}$ & $\begin{array}{l}\text { broad-based un- } \\
\text { steady gait \& } \\
\text { mild bilat upper- } \\
\text { extremity dys- } \\
\text { metria }\end{array}$ & $\begin{array}{l}\text { CT ventriculogram revealed a } \\
\text { giant cyst originally interpreted } \\
\text { as intraventricular at the atrium } \\
\text { of the rt lat ventricle; cyst in } \\
\text { the } 4 \text { th ventricle }\end{array}$ & $\begin{array}{l}\text { endoscopic evacuation } \\
\text { of } 4 \text { th ventricle cysts } \\
\text { via cisterna magna; rt } \\
\text { occipital burr hole, } \\
\text { transventricular ap- } \\
\text { proach to quadrigem- } \\
\text { inal cistern \& evacu- } \\
\text { ation of multiple cysts }\end{array}$ & $\begin{array}{l}\text { hospital course com- } \\
\text { plicated by staph- } \\
\text { ylococcus ventric- } \\
\text { ulitis; subsequent } \\
\text { VP shunt; neuro- } \\
\text { logically intact \& } \\
\text { asymptomatic at 6- } \\
\text { mo follow up }\end{array}$ \\
\hline 3 & $24, \mathrm{M}$ & $\begin{array}{l}1 \text { mo of headache \& } \\
\text { nausea; episode of } \\
\text { syncope; known } \\
\text { history of parenchy- } \\
\text { mal NCC \& seizures }\end{array}$ & $\begin{array}{l}\text { upper-extremity } \\
\text { tremor }\end{array}$ & $\begin{array}{l}\text { CT \& MR demonstrated a } 1.5-\mathrm{cm} \\
\text { ring-enhancing cystic velum in- } \\
\text { terpositum causing obstruction of } \\
\text { foramen of Monro }\end{array}$ & $\begin{array}{l}\text { 2-port endoscopic removal } \\
\text { of cysts via rt frontal } \\
\text { transventricular approach; } \\
\text { septum pellucidotomy }\end{array}$ & $\begin{array}{c}\text { neurologically intact } \\
\& \text { asymptomatic } \\
\text { at } 1-\mathrm{yr} \text { follow up }\end{array}$ \\
\hline
\end{tabular}




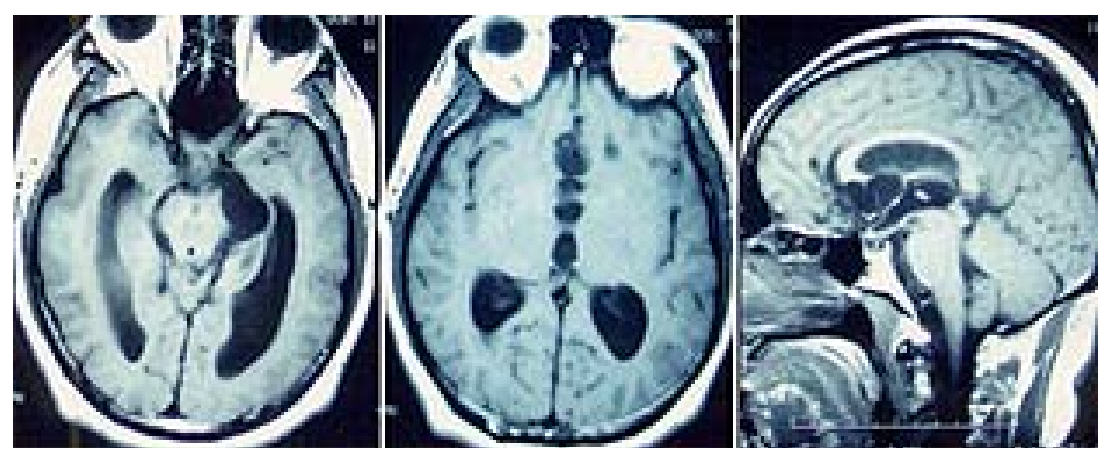

Fig. 1. Case 1. Axial $\mathrm{T}_{1}$-weighted MR images (left and center) demonstrating nonenhancing interhemispheric and left premesencephalic cysts. Midsagittal $\mathrm{T}_{1}$-weighted MR image demonstrating the extent of the NCC cyst.

tis, a CSF shunt was placed after he could not be weaned from external drainage. Based on the findings of CSF within the fourth ventricle and cisterna magna, a CSF shunt was placed in the other patient (Case 2).

\section{DISCUSSION}

In this report we present a minimally invasive approach to the extirpation of cisternal cysticercosis cysts. In two of our cases, the neurological effects (obstructive hydrocephalus and optic apparatus compression) of the localized mass lesion were alleviated by removal of the cysts. In the third case it was demonstrated that the quadrigeminal cistern could safely be accessed endoscopically. The purpose

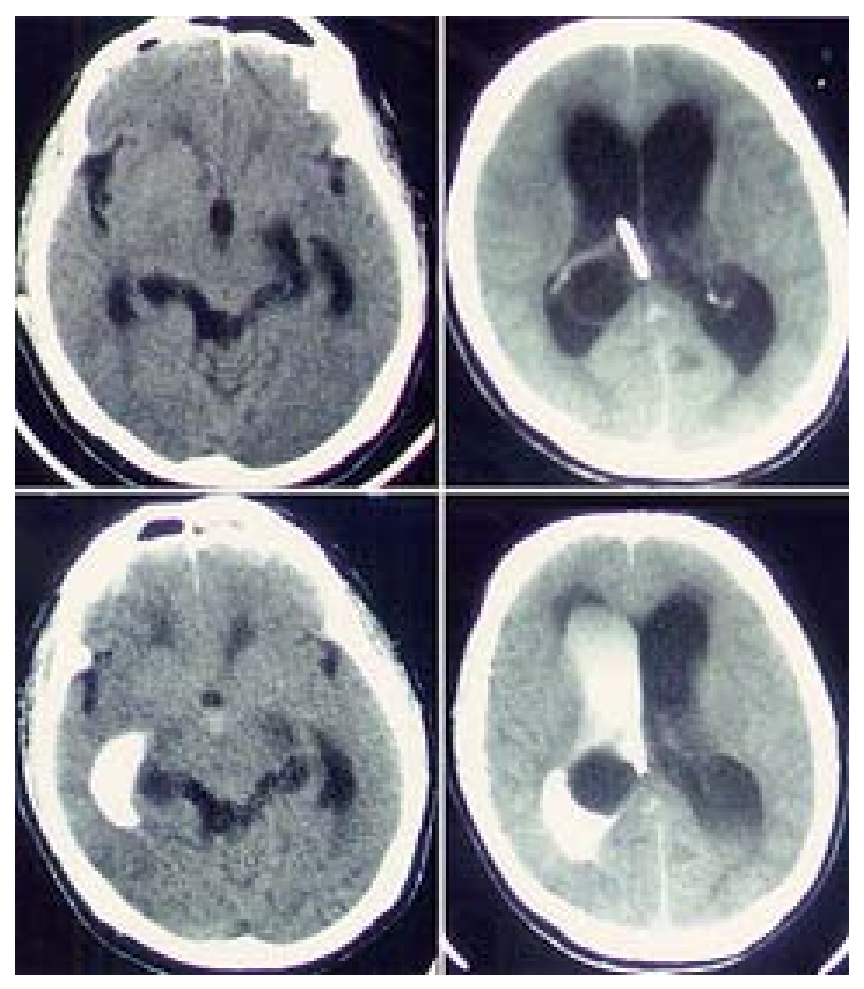

Fig. 2. Case 2. Postventriculostomy CT scans revealing a right quadrigeminal cyst that extends into the atrium of the right lateral ventricle. of this report was not to promote the removal of all cisternal NCC cysts but rather to illustrate that in selected cases this technique was a good alternative or supplement to standard treatment. In our three cases, treatment of the cisternal cysts by standard (nonendoscopic) open microsurgical techniques would have required a craniotomy and either a larger corticectomy or some degree of brain retraction.

Some practitioners have advocated a conservative approach to the management of cisternal cysticercosis. ${ }^{22,29}$ They have contended that the natural history of cysticercosis is benign and that most cysts simply die and "burnout" within 10 or 20 years. It has been argued that only the associated hydrocephalus needs to be treated because the disease is self limited. This argument arises from the observation that parenchymal cysts often become calcified and die after a period of time. There are, however, numerous accounts of the much higher rates of mortality and morbidity resulting from cisternal cysts because of their propensity to cause direct mass effect on the midbrain and brainstem, as well as inflammation leading to arachnoiditis, cranial neuropathies, and vasculitis. 2,4,10,11,19,23,27,36,39,40

Cisternal lesions have been treated medically by administering antiparasitic agents albendazole and praziquantel. ${ }^{15,16,22}$ Authors of case reports have suggested that these agents prevent further expansion of the cystic lesions and in some cases reduce the size of the subarachnoid cysts. Relapses, however, frequently occur. ${ }^{40}$ The efficacy of albendazole and praziquantel is debatable. A number of authors have asserted the benefit of medical treatment: ${ }^{15,16,22}$ however, no large scale prospective studies have been conducted. In a review of the randomized controlled trials published since 1966, Salinas, et al. ${ }^{34}$ concluded that there is insufficient evidence that medical therapy for NCC provides any clinical benefit. Furthermore, it is thought that CSF concentrations of albendazole and praziquantel are lower than those in the parenchyma ${ }^{40}$ making medical management even more unlikely to treat cisternal NCC adequately.

Several authors have reported the extirpation of these cysts by open craniotomy or aspiration via CT-guided stereotactic puncture. ${ }^{12,26,31,38}$ The very nature of the disease, however, makes traditional surgical procedures inherently risky. These are deep-seeded lesions that may be difficult to access. Skull base approaches may be required to reach and excise the lesions. 


\section{T. Gravori, T. Steineke, and M. Bergsneider}

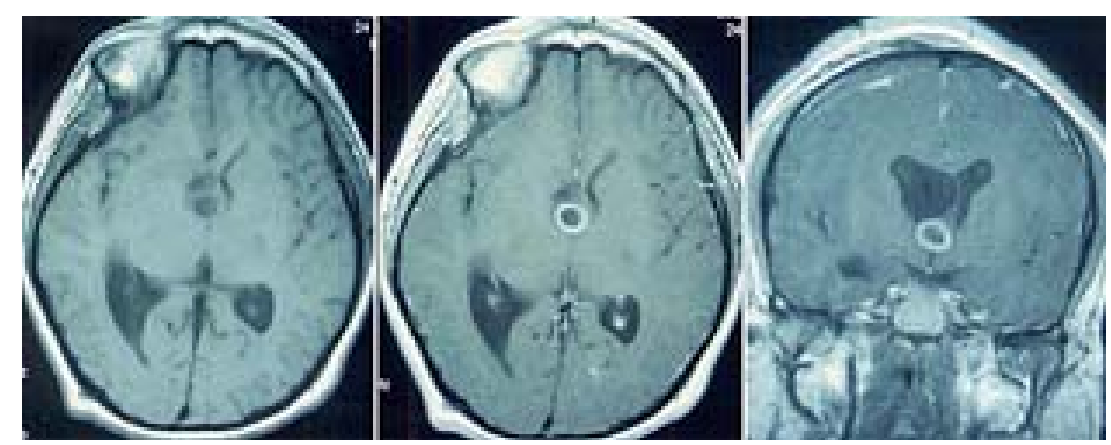

Fig. 3. Case 3. Left and Center: Axial MR images with and without gadolinium demonstrating a ring-enhancing lesion at the foramen of Monro. Right: Postgadolinium coronal MR image was better at demonstrating the cyst localized to the third ventricular vellum.

A relative contraindication to resection (including that assisted by endoscopy) of cisternal cysts is the presence of significant inflammation, which is typically demonstrated by extensive enhancement of the cisterns and cysts on MR images. In these cases, the arachnoid and cyst walls are often opaque and indistinguishable, making exploration and removal of the cysts difficult and hazardous. If surgical exploration is considered, a low threshold for converting from the excision to placement of a shunt must be maintained. The preoperative use of steroid therapy must also be considered and may prove beneficial.

Not all cisternal cysts are amenable to endoscopic excision. In each of our cases there were cysts that could be approached via a transventricular route (and associated hydrocephalus). Cysts in the cerebellopontine angle or anterior to the brainstem are likely poor candidates for any surgical approach.

\section{CONCLUSIONS}

In this report we demonstrate that removal of cisternal lesions can be both safe and feasible when combining a minimally invasive keyhole procedure with endoscopy. Patients with symptomatic cisternal lesions caused by mass effect (namely, obstructive hydrocephalus or brainstem compression-induced focal deficits) should be considered for this treatment if circumstances permit. Future studies need to be undertaken to assess the efficacy of antiparasitic medications combined with minimally invasive resection for the treatment of cisternal lesions. Furthermore, as experience with endoscopic procedures increases in combination with future technical advances, expiration of nonsymptomatic lesions may be recommended to prevent the late-onset complications of inflammation, arachnoiditis, vasculitis, and ischemia. In applying minimally invasive techniques and endoscopically assisted surgery to the treatment of cisternal NCC, the goal is twofold: 1) to benefit from cyst expiration and 2) to minimize and ultimately eliminate the risks associated with open procedures.

\section{References}

1. Alarcon F, Hidalgo F, Moncayo J, et al: Cerebral cysticercosis and stroke. Stroke 23:224-228, 1992
2. Bang OY, Heo JH, Choi SA, et al: Large cerebral infarction during praziquantel therapy in neurocysticercosis. Stroke 28: 211-213, 1997

3. Barinagarrementeria F: Non-vascular aetiology of lacunar syndromes. J Neurol Neurosurg Psychiatry 53:1111, 1990

4. Barinagarrementeria F, Cantu C: Frequency of cerebral arteritis in subarachnoid cysticercosis: an angiographic study. Stroke 29:123-125, 1998

5. Barinagarrementeria F, Cantu C: Neurocysticercosis as a cause of stroke. Stroke 23:1180-1181, 1992

6. Barinagarrementeria F, Del Brutto OH: Lacunar syndrome due to neurocysticercosis. Arch Neurol 46:415-417, 1989

7. Barinagarrementeria F, Del Brutto OH: Neurocysticercosis and pure motor hemiparesis. Stroke 19:1156-1158, 1988

8. Bergsneider M: Endoscopic removal of cysticercal cysts within the fourth ventricle. Technical note. J Neurosurg 91:340-345, 1999

9. Bergsneider M, Holly LT, Lee JH, et al: Endoscopic management of cysticercal cysts within the lateral and third ventricles. J Neurosurg 92:14-23, 2000

10. Cantu C, Barinagarrementeria F: Cerebrovascular complications of neurocysticercosis. Clinical and neuroimaging spectrum. Arch Neurol 53:233-239, 1996

11. Cantu C, Villarreal J, Soto JL, et al: Cerebral cysticercotic arteritis: detection and follow-up by transcranial Doppler. Cerebrovasc Dis 8:2-7, 1998

12. Couldwell WT, Zee CS, Apuzzo ML: Definition of the role of contemporary surgical management in cisternal and parenchymatous cysticercosis cerebri. Neurosurgery 28:231-237, 1991

13. Del Brutto O, Barinagarrementeria F: Inflammatory arteriopathies and pure motor hemiplegia. Arch Neurol 46:361, 1989

14. Del Brutto OH: Neurocysticercosis. Curr Opin Neurol 10: 268-272, 1997

15. del Brutto OH, Sotelo J: Albendazole therapy for subarachnoid and ventricular cysticercosis. Case report. J Neurosurg 72: 816-817, 1990

16. Del Brutto $\mathrm{OH}$, Sotelo J, Aguirre R, et al: Albendazole therapy for giant subarachnoid cysticerci. Arch Neurol 49:535-538, 1992

17. Del Brutto OH, Sotelo J, Roman GC: Neurocysticercosis: A Clinical Handbook. Exton, PA: Swets \& Zeitlinger, 1998

18. Escobar A: The pathology of neurocysticercosis, in Palacios E, Rodriguez-Carbajal J, Taveras JM (eds): Cysticercosis of the Central Nervous System. Springfield, IL: Charles C Thomas, 1983, pp 27-54

19. Estanol B, Corona T, Abad P: A prognostic classification of cerebral cysticercosis: therapeutic implications. J Neurol Neurosurg Psychiatry 49:1131-1134, 1986

20. Jha S, Kumar V: Neurocysticercosis presenting as stroke. Neurol India 48:391-394, 2000 


\section{Endoscopy for cisternal cysticercal cysts}

21. Latovitzki N, Abrams G, Clark C, et al: Cerebral cysticercosis. Neurology 28:838-842, 1978

22. Leblanc R, Knowles KF, Melanson D, et al: Neurocysticercosis: surgical and medical management with praziquantel. Neurosurgery 18:419-427, 1986

23. Levy AS, Lillehei KO, Rubinstein D, et al: Subarachnoid neurocysticercosis with occlusion of the major intracranial arteries: case report. Neurosurgery 36:183-188, 1995

24. Lobato RD, Lamas E, Portillo JM, et al: Hydrocephalus in cerebral cysticercosis. Pathogenic and therapeutic considerations. J Neurosurg 55:786-793, 1981

25. Loyo M, Kleriga E, Estanol B: Fourth ventricular cysticercosis. Neurosurgery 7:456-458, 1980

26. Martinez-Lopez M, Quiroz y Ferrari F: Cysticercosis. J Clin Neuroophthalmol 5:127-143, 1985

27. McCormick GF: Cysticercosis-review of 230 patients. Bull Clin Neurosci 50:76-101, 1985

28. Monteiro L, Almeida-Pinto J, Stocker A, et al: Active neurocysticercosis, parenchymal and extraparenchymal: a study of 38 patients. J Neurol 241:15-21, 1993

29. Oka Y, Fukui K, Shoda D, et al: Cerebral cysticercosis manifesting as hydrocephalus - case report. Neurol Med Chir 36: 654-658, 1996

30. Pittella JE: Neurocysticercosis. Brain Pathol 7:681-693, 1997

31. Ramina R, Hunhevicz SC: Cerebral cysticercosis presenting as mass lesion. Surg Neurol 25:89-93, 1986

32. Revuelta Gutierrez R, Soto-Hernandez JL, Suastegui-Roman R, et al: Transient hemifacial spasm associated with subarachnoid brainstem cysticercosis: a case report. Neurosurg Rev 21: 167-170, 1998
33. Revuelta R, Juambelz P, Balderrama J, et al: Contralateral trigeminal neuralgia: a new clinical manifestation of neurocysticercosis: case report. Neurosurgery 37:138-140, 1995

34. Salinas R, Counsell C, Prasad K, et al: Treating neurocysticercosis medically: a systematic review of randomized, controlled trials. Trop Med Int Health 4:713-718, 1999

35. Shanley JD, Jordan MC: Clinical aspects of CNS cysticercosis. Arch Intern Med 140:1309-1313, 1980

36. Soto-Hernandez JL, Gomez-Llata Andrade S, Rojas-Echeverri LA, et al: Subarachnoid hemorrhage secondary to a ruptured inflammatory aneurysm: a possible manifestation of neurocysticercosis: case report. Neurosurgery 38:197-200, 1996

37. Stern WE: Neurosurgical considerations of cysticercosis of the central nervous system. J Neurosurg 55:382-389, 1981

38. Torrealba G, Del Villar S, Tagle P, et al: Cysticercosis of the central nervous system: clinical and therapeutic considerations. J Neurol Neurosurg Psychiatry 47:784-790, 1984

39. White AC Jr: Neurocysticercosis: a major cause of neurological disease worldwide. Clin Infect Dis 24:101-115, 1997

40. White AC Jr: Neurocysticercosis: updates on epidemiology, pathogenesis, diagnosis, and management. Annu Rev Med 51: 187-206, 2000

Manuscript received May 6, 2002.

Accepted in final form May 17, 2002.

Address reprint requests to: Marvin Bergsneider, M.D., 100 University of California, Los Angeles Medical Plaza, Suite 219, Los Angeles, California 90024. email: mbergsneider@mednet.ucla.edu. 